\title{
Epidemiological changes in measles infections in southern China between 2009 and 2016: a retrospective database analysis
}

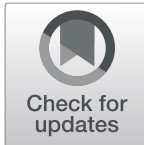

Huizhen Zheng ${ }^{1 \dagger}$, Katherine Min Jia ${ }^{2 *}$, Riyang Sun ${ }^{2}$, Pui Hu${ }^{1}$, Maggie Haitian Wang ${ }^{2,3}$, Benny Chung-Ying Zee ${ }^{2,3}$, Wenjia Liang $^{1 *}$ and Ka Chun Chong ${ }^{2,3^{*}}$

\begin{abstract}
Background: The incidence rate of measles in China reached a nadir in 2012 after 2 supplementary immunization activities (SIAs) were undertaken in 2009 and 2010. However, the disease began re-emerging in 2013, with a high prevalence rate observed in 2013-2014 in the southern province of Guangdong. In this study, we assessed the changes that occurred in measles epidemiology during 2009-2016, particularly between 2009 and 2011 (when the influence of the SIAs were in full effect) and between 2012 and 2016 (when this influence subsided).

Methods: Data from 22,362 patients with measles diagnosed between 2009 and 2016, and whose diagnoses were confirmed clinically and/or with laboratory testing, were extracted from the National Infectious Disease Monitoring Information System. Descriptive analyses were performed, and changes in epidemiological characteristics between 2009 and 2011 and 2012-2016 were compared.

Results: There was a substantial surge in 0-8-month-old patients after 2012; the incidence rate increased from 4.0 per 100,000 population in 2011 (10.3\% of the total) to 280 per 100,000 population in 2013 (32.8\% of the total). Patients aged 0-6 years represented 73.4\% of the total increase between 2011 and 2013. Compared with 2009-2011, adults aged $\geq 25$ years accounted for a higher proportion of patients in 2013 and after $(p<0.01)$, and were highest in 2016 (31\% of the patient total).

Conclusion: Despite the remarkable results achieved by SIAs in terms of providing herd immunity, the 2013 resurgence of measles revealed insufficient immunization coverage among children. Therefore routine immunization programs should be strengthened, and supplementary vaccinations targeting adults should also be contemplated.
\end{abstract}

Keywords: Supplementary immunization, Vaccine, Child infections, Measles, China, Measles-mumps-rubella

\footnotetext{
*Correspondence: katherine.jia19@imperial.ac.uk; liangwenjia@163.com; marc@cuhk.edu.hk

${ }^{+}$Huizhen Zheng and Katherine Min Jia contributed equally to this work.

${ }^{2}$ Jockey Club School of Public Health and Primary Care, The Chinese University of Hong Kong, Hong Kong, China

${ }^{1}$ Center for Disease Control and Prevention of Guangdong Province, Guangzhou, China

Full list of author information is available at the end of the article
}

C C The Author(s). 2020 Open Access This article is licensed under a Creative Commons Attribution 4.0 International License, which permits use, sharing, adaptation, distribution and reproduction in any medium or format, as long as you give appropriate credit to the original author(s) and the source, provide a link to the Creative Commons licence, and indicate if changes were made. The images or other third party material in this article are included in the article's Creative Commons licence, unless indicated otherwise in a credit line to the material. If material is not included in the article's Creative Commons licence and your intended use is not permitted by statutory regulation or exceeds the permitted use, you will need to obtain permission directly from the copyright holder. To view a copy of this licence, visit http://creativecommons.org/licenses/by/4.0/ The Creative Commons Public Domain Dedication waiver (http://creativecommons.org/publicdomain/zero/1.0/) applies to the data made available in this article, unless otherwise stated in a credit line to the data. 


\section{Background}

Measles is a highly contagious disease caused by the rubeola virus, which has been in continuous global circulation and has significantly contributed to the worldwide disease burden. With the widespread use of measles vaccines (MVs), the incidence rate of measles has substantially decreased in most countries. Nevertheless, the disease still causes high morbidity and mortality among children worldwide, and 95\% of measles-related deaths occur in lowincome countries with weak healthcare infrastructures [1].

China began deploying the MV in the 1960s and incorporated it into the routine immunization schedule under the national expanded immunization program in 1978, wherein a single dose of MV was administered free-ofcharge to infants aged 8 months. Routine immunization with 2 MV doses commenced in 1985, with the first and second doses administered at the eighth month and the seventh year of age, respectively; the age of the second dose was lowered to 18-24 months in 2005 [2]. In 2006, China launched the 2006-2012 National Action Plan for Measles Elimination, following which the incidence of measles was kept at a low rate mainly owing to enhanced routine immunization coupled with supplementary immunization activities (SIAs), which were mass immunization campaigns that targeted all individuals in a specific age range regardless of their immunization history [3-5]. The purpose of the SIAs was to rapidly close the immunity gap within the targeted populations while providing herd immunity to newborns and older individuals. Unsynchronized provincewide SIAs involving MV administration were introduced in 27 provinces between 2003 and 2009 [4], and a national synchronized SIA was implemented in 2010 [3]. Although this program achieved great strides towards eradicating measles, a national resurgence of the disease occurred in 2013 along with changes in the epidemiological characteristics of measles infections [3, 6-9].

Guangdong, a province in southern China, had a high and increasing measles incidence rate before 2009, with 21.2 per 100,000 population (the highest among all provinces) in 2007 and 19.1 per 100,000 population in 2008 [10]. Despite the 2009 province-wide and 2010 nationwide SIAs, the number of measles cases began to surge in 2012 and was most notable in 2013 (accompanied by a national resurgence) [11]. Guangdong had the highest measles incidence rate nationwide in both 2012 and 2013 , and the second highest in 2014, and accounted for 30,25 and $12.8 \%$ of the nationwide patients with measles in the three years respectively [6, 7]. As the province with the largest population, Guangdong comprised $7.61 \%$ of the national population in 2011 and is critical to the country's efforts towards eliminating measles [12]. In this study, we aimed to investigate the changes in measles epidemiology during 2009-2016, particularly in terms of how the distribution of patients by age altered between the two periods of 2009-2011 (when the effects of the SIAs were in force) and 2012-2016 (when their effects diminished). Our findings can provide the epidemiological basis for improving immunization strategies for measles elimination in the province.

\section{Methods \\ Setting}

Guangdong province has an area of $179,700 \mathrm{~km}^{2}$ and comprised 108 million inhabitants in 2015, 28.0 million of whom were migrants from other provinces [13]. The province hosts China's largest floating population [14], defined as residents whose locations of household registration are in other provinces [15]. The province generally administers two doses of routine immunizations for children, with the first dose of MV (MV1) administered at the 8th month and the second dose (MV2) at 18-24 months of age $[4,16]$. In 2009, all 8-month-old to 14-year-old individuals were vaccinated as part of a province-wide SIA, regardless of their immunization status. According to internal data from the Centers for Disease Control and Prevention (CDC) of Guangdong Province, approximately 20 million children were vaccinated during the 2009 SIAs, achieving an administrative coverage of $97.6 \%$. The 2010 SIAs targeted the entire 8-month-old to 4-year-old population, with 5,603,504 children vaccinated (a coverage of $97.1 \%$ ).

\section{Data}

The measles data gathered between January 2009 and December 2016 were extracted from the National Infectious Disease Monitoring Information System (NIDMIS) by the Guangdong CDC. Two types of cases were included: clinically confirmed and laboratory test-confirmed. For laboratory-confirmed case, the blood samples collected from suspected cases within 3 days after the onset of symptoms (e.g. rash) were sent to the CDC laboratory for testing of measles-specific immunoglobulin M (IgM). The IgM test was performed using standard enzyme-linked immunosorbent assay (ELISA) method (Virion/SerionGmbH, Würzburg, Germany). Real-time polymerase chain reaction (RT-PCR) assay was used to evaluate around $10 \%$ of cases every year for a quality control. All the laboratory tests were conducted based on the internal operating procedure for measles surveillance. For clinically confirmed patients, those presenting with typical symptoms (i.e., a body temperature $>38^{\circ} \mathrm{C}$ and a maculopapular rash accompanied by coryza, cough, or conjunctivitis) who were diagnosed with measles were reported to the CDC through the NIDMIS within $6 \mathrm{~h}$ by out- and in-patient doctors. If laboratory capacity allowed, blood samples from these patients were sent to the CDC clinical laboratories for confirmation. Serum samples were prepared according to the CDC laboratory standard operating procedures. If the laboratory capacity was insufficient, an epidemiological investigation 
was conducted to assess whether the suspected case had any potential exposure to other patients 7-23 days (a maximum number of 24 days in CDC practice) prior to rash onset.

The vaccination history was retrieved from the Immunization Information Management System of the Guangdong $\mathrm{CDC}$, which is an electronic registry for storing individual-level immunization information for individuals born in 2005 and after. Those born in 2004 or earlier could only have their immunization records checked through paper-based hospital records or via recollection (memory).

\section{Statistical analysis}

We conducted descriptive analyses on the epidemiological trends of measles in Guangdong during 20092016. The collected data included the date of disease onset, vaccination history, age, sex, household registration, and city of residence; calculations were based on incidences by age group, sex, household registration, and city of residence. Incidence was expressed as the number of reported patients divided by the group's population size [3]. We used a heat map to represent the spatial distribution of patients in each city at the prefecture level. Changes in measles infection rates by age group, sex, and household registration were compared between the 2 periods of 2009-2011 and 2012-2016. Age was categorized into six groups: $0-8$ months (although infants should have been vaccinated at the 8th months, it takes 1-2 weeks for protective antibody titers to develop [17]), 9-23 months (after having received MV1, a majority of children received MV2 at 18-24 months), 2-6 years, 715 years (primary and junior high school students under compulsory education), 16-25 years (senior high school students and young adults), and $\geq 26$ years (adults). Vaccination histories of patients in different age groups were also compared.

We compared the proportions of cases between the 2 periods, categorized by sex, household registration and age groups, using Pearson's chi-square tests. Statistical analyses were performed using SAS 9.4 (SAS Institute Inc., Cary, NC, USA) and the $\mathrm{R} 3.3 .3$ software ( $\mathrm{R}$ Foundation for Statistical Computing, Vienna, Austria) [18]. $P$-values $<0.05$ were considered statistically significant.

\section{Ethical considerations}

This study was reviewed and approved by the Medical Ethics Committee of the Guangdong CDC. Informed consent was waived by the Committee, as the data were collected for the purpose of routine public health surveillance activities. The data were anonymized before analysis.

\section{Results}

\section{Overall assessment}

During 2009-2016, 22,362 cases of measles were reported to the Guangdong CDC. The annual rate of reported cases ranged between 0.3 per 100,000 population (2011) and 6.6 per 100,000 population (2013); the mean annual incidence was 2.6 per 100,000 population.

Measles cases decreased by $71.5 \%$ from 2246 (2.2/100, $000)$ in 2009 to $640(0.6 / 100,000)$ in 2010, and reached a nadir of 308 cases $(0.3 / 100,000)$ in 2011. A large-scale resurgence began in April 2012, and 1929 cases were reported that year $(1.8 / 100,000)$, followed by a further increase to 7032 cases $(6.6 / 100,000)$ in 2013. A monthly peak of 1442 cases was recorded in June 2014 (the highest in the study period); despite this, the annual number decreased slightly to $6752(6.3 / 100,000)$. The number decreased again to $2190(2.0 / 100,000)$ in 2015 , where the monthly reported cases were only ranging $24-45 \%$ of their corresponding levels in 2014, and further to 1265 $(1.2 / 100,000)$ in 2016 (Fig. 1).

\section{Distribution by city}

Figure 2 shows the yearly incidence in 21 prefecturelevel cities in Guangdong during 2009-2016. During the resurgence, 16 of 21 cities had incidences $>1$ per 100 , 000 population in 2013, rising to 18 cities in 2014. In 2013, 4 southern and southwestern cities contributed to $61.2 \%$ of the total increase in the number of patients since 2012: Guangzhou $(n=1186 ; 9.2 / 100,000)$, Shenzhen $(n=1086 ; 10.2 / 100,000)$, Zhanjiang $(n=927 ; 12.9$ / $100,000)$, and Huizhou $(n=734 ; 15.6 / 100,000)$. Over half of the patients during 2013-2014 (54.7\%) were from these 4 cities (Fig. 2).

\section{Distribution by sex and household registration}

During 2009-2016, there were 13,117 male and 9245 female patients diagnosed with measles, with an average annual ratio of 1.4:1 (compared to $1.1: 1$ in the general population). The proportions of patients by sex did not change significantly between 2009 and 2011 and 20122016 ( $p=0.43)$ (Table 1).

Regarding household registration, $30 \%$ of total cases occurred among the non-locals (i.e. migrant workers) in 2009-2016. Non-local patients generally had higher incidences than their local counterparts (Table 1). However, cases with known local household registration status increased significantly in proportion during 2012-2016 compared to 2009-2011 $(p<0.01)$.

\section{Age groups}

The median age at disease onset was 19 months (Table 2). The 0-8 month and 9-23 month age groups had the highest mean annual incidence, with the most number of patients, while adults aged $\geq 25$ accounted for increasingly 


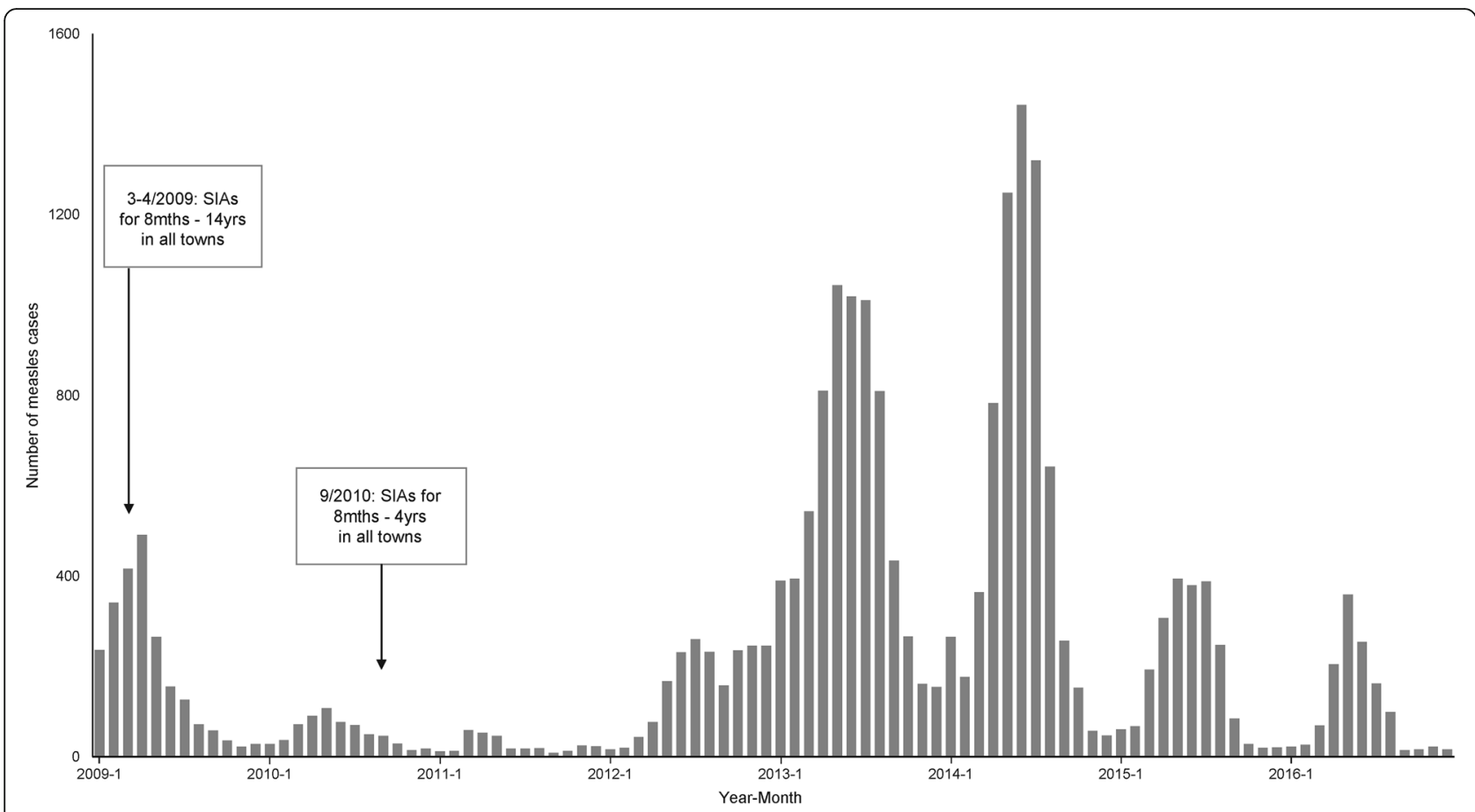

Fig. 1 Measles monthly reported cases and province-wide immunization activities in Guangdong province (2009-2016)

higher proportions of patients between 2013 and 2016 (Fig. 3).

Overall, the number of patients with measles decreased rapidly across all age groups (by 75-90\%) during 20092011 (Table 2 and Fig. 3). During 2009-2011, the 9-23 months group had the highest number of patients, and, combined with the 0-8 months group, accounted for 30$50 \%$ of patients each year (Table 1 ). Those aged $7-15$ years, followed by those aged 2-6 years represented the lowest number of patients. The $16-24$ years and $\geq 25$ years groups combined represented $30-40 \%$ of the patients each year.

In 2012, measles incidence rates surged in every age group, particularly the three youngest (Table 2). During 2013-2014, the 0-8 months group comprised the highest number of patients: $2306(280 / 100,000)$ in 2013 and 2124 $(255 / 100,000)$ in 2014 . The $0-8$ month, $9-23$ month, and 2-6 year groups comprised approximately $70 \%$ of all patients in 2012-2014, and represented 73.4\% of the total increase in cases in 2012-2014 when compared to 20092011. The proportion of patients aged $\geq 25$ years had also been increasing since 2013 (most remarkably in 2014), and became the highest-afflicted group in 2016 (31\% of the total patients) (Fig. 3).

In the 9-23 months group, approximately $90 \%$ of patients were 9-18 months old who should have taken MV1. Thus, $82-91 \%$ of the observed yearly increases and decreases in the 9-23 months group were attributable to those 9-18 months of age. The proportion of 0 8 -month-old patients increased significantly from $17.2 \%$ in $2009-2011$ to $30.6 \%$ in $2012-2016$, and comprised the highest number of patients overall $(p<0.01)$. A significant increase was also observed in the $\geq 25$ years group $(p<0.01)$, while the proportions of patients decreased in the 7-15 years $(p<0.01)$ and $16-24$ years $(p<0.01)$ groups (Table 1$)$.

\section{Vaccination status of the patients by age group}

Table 3 shows the vaccination statuses of the patients during 2009-2011 and 2012-2016. In 2009-2011, 32.6\% of the patients in the 9-23 months group had received MV1. During 2012-2016, the majority of patients among the 3 youngest groups were unvaccinated, while the majority of those among the older groups had unknown histories.

\section{Discussion}

The incidence of measles in Guangdong Province dropped to a very low level in 1-2 years after the SIAs were introduced but resurged afterwards; this was also the trend in other regions of China [19-21]. Infants aged $0-8$ months were the main group for the resurgence of measles, which was also the case nationwide [6]. As indicated by some studies, this can be explained by the $0-8$ month-old patients being the most susceptible to measles outbreaks among all age groups. Although infants had immunity acquired from their mothers, most had this immunity waned in 6-8 month.

A sero-survey performed in Guangdong in 2013 revealed that only $23.58 \%$ of infants who were $4-5$ months 


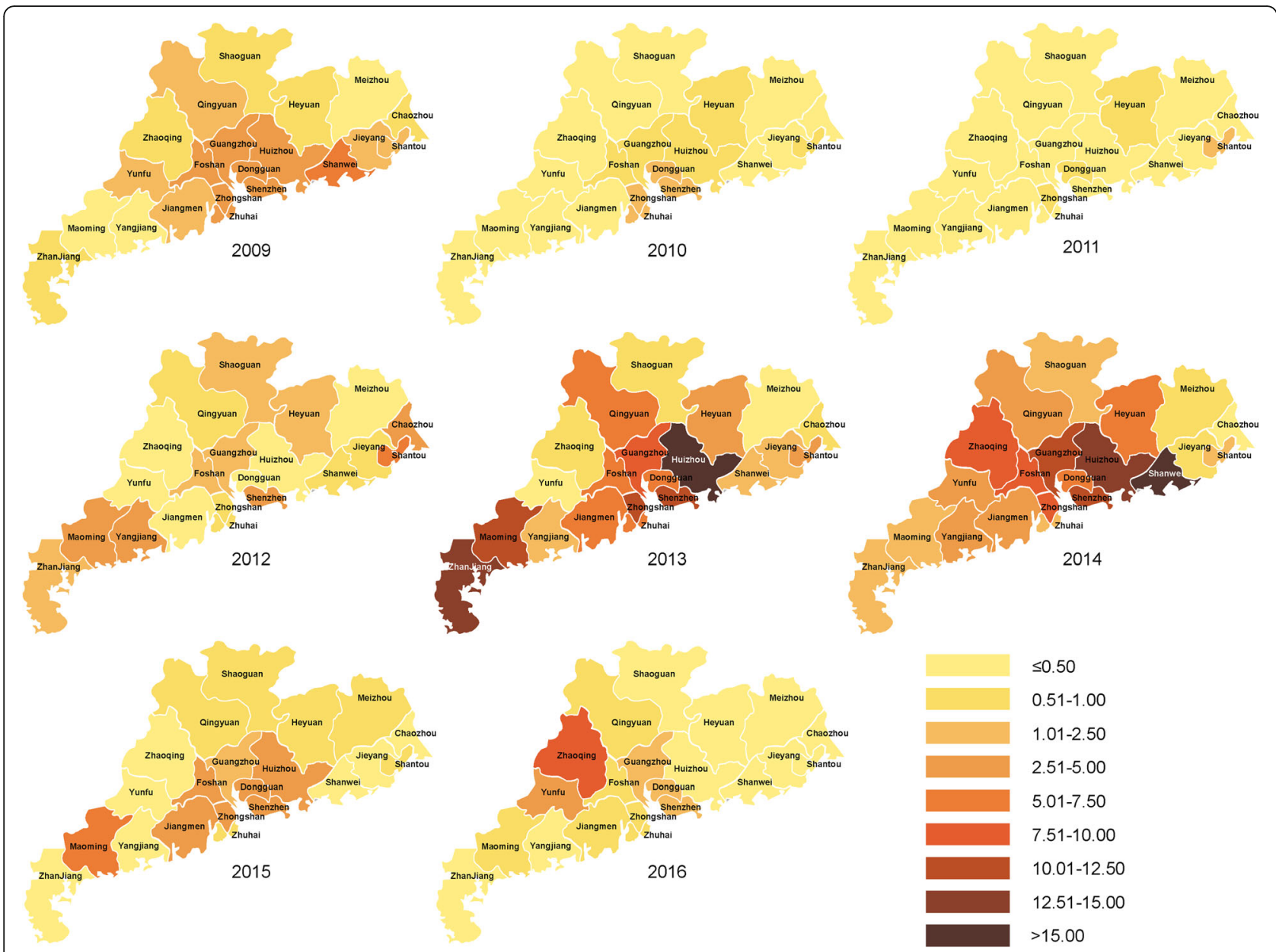

Fig. 2 Spatial distribution of cases (per 100,000) in 21 prefecture-level cities of Guangdong

old were seropositive, as were only $10.53 \%$ of those $6-7$ months old and $54.17 \%$ of those $8-9$ months old [22]. Another serological study conducted in Guangdong found that infants as young as three months of age were sometimes seronegative if their mothers had low levels of measles antibodies [23]. Even women who have acquired natural immunity or been vaccinated may not transmit sufficient amounts of maternal antibodies to protect their infants during their first eight months of life. Based on these data, the majority of 6-8-month-old infants appear to be particularly susceptible to measles (i.e., have a "zero defense" status) $[22,24]$. Moreover, the proportion of unprotected infants is high because mothers nowadays mostly acquire their immunity from vaccinations (especially those born after 1985 when 2-dose MVs were introduced) rather than from natural infections; hence, infants have less transmitted immunity with shorter protective durations [25, 26]. Nevertheless, a Belgian study in a nearly eliminated setting showed that maternal immunity actually waned at an early age in the children of both vaccinated and unvaccinated mothers [27, 28]; this warrants further investigation.
We conducted a further analysis of children who were too young for routine immunization (See Additional file 1). Those who were six to eight months of age comprised nearly $80 \%$ of all infants $\leq 8$ months infected annually; a large percentage had therefore lost maternally transmitted immunity. Every group had almost the same proportion of cases during 2012-2016 as they did in 2009-2010; during the 2013-2014 resurgence, there was no increase in the proportion of infants $<6$ month of age who were infected. Our evidence cannot draw conclusion on the relationship between resurgence and the trend of waning immunity, due to the lack of serological data, but the large proportion of 6-8 months old cases had indicated the need to pay attention to the immunity gap between when infants' maternal immunity waned and vaccination administration at the eighth month. China's immunization schedule administers MV1 at eight months of age, which is earlier than the World Health Organization's recommendation (nine months) [29]. In general, maternal immunity that has not yet waned may interfere with the vaccine-induced immune response and result in vaccination failure [30]. 
Table 1 Distribution of cases by sex, household registration and age group in 2009-11 and in 2012-16

\begin{tabular}{|c|c|c|c|c|c|c|c|}
\hline & \multirow[b]{2}{*}{ n (\%) } & \multicolumn{3}{|l|}{ 2009-11 } & \multicolumn{3}{|l|}{$2012-16$} \\
\hline & & $\begin{array}{l}\text { Proportion of } \\
\text { Guangdong } \\
\text { population }^{\text {a }}\end{array}$ & $\begin{array}{l}\text { Averaged incidence } \\
\text { (Cases reported } \\
\text { per 100,000) }\end{array}$ & n (\%) & $\begin{array}{l}\text { Proportion of } \\
\text { Guangdong } \\
\text { population }^{\text {a }}\end{array}$ & $\begin{array}{l}\text { Averaged incidence } \\
\text { (Cases reported } \\
\text { per 100,000) }\end{array}$ & $p$-value ${ }^{b}$ \\
\hline Overall & 3194 & & & 19,168 & & & \\
\hline \multicolumn{8}{|l|}{ Sex } \\
\hline Male & 1853 (58.0\%) & $52.0 \%$ & 1.18 & 11,264 (58.8\%) & $52.5 \%$ & 4.01 & 0.43 \\
\hline Female & 1341 (42.0\%) & $48.0 \%$ & 0.90 & 7904 (41.2\%) & $47.5 \%$ & 3.10 & \\
\hline \multicolumn{8}{|c|}{ Household registration $^{c}$} \\
\hline Local & 1777 (55.6\%) & $79.4 \%$ & 0.72 & 13,000 (67.8\%) & $76.1 \%$ & 3.17 & $<0.01$ \\
\hline Non-local & $951(29.8 \%)$ & $20.6 \%$ & 1.47 & 6084 (31.7\%) & $23.8 \%$ & 4.90 & \\
\hline \multicolumn{8}{|l|}{ Age groups } \\
\hline 0-8 months & $548(17.2 \%)$ & $0.8 \%$ & 22.71 & $5862(30.6 \%)$ & $0.8 \%$ & 142.24 & $<0.01$ \\
\hline 9-23 months & 769 (24.1\%) & $1.5 \%$ & 16.40 & 4551 (23.7\%) & $1.7 \%$ & 49.09 & 0.68 \\
\hline 2-6 years & 473 (14.8\%) & $4.8 \%$ & 3.12 & $2646(13.8 \%)$ & $5.2 \%$ & 9.61 & 0.13 \\
\hline $7-15$ years & 315 (9.9\%) & $14.1 \%$ & 0.63 & 761 (4.0\%) & $10.4 \%$ & 1.37 & $<0.01$ \\
\hline 16-24 years & $558(17.5 \%)$ & $18.0 \%$ & 1.03 & 1431 (7.5\%) & $19.2 \%$ & 1.39 & $<0.01$ \\
\hline$\geq 25$ years & $531(16.6 \%)$ & $60.7 \%$ & 0.29 & 3917 (20.4\%) & $62.7 \%$ & 1.16 & $<0.01$ \\
\hline
\end{tabular}

${ }^{a}$ Averaged proportion of the total population in Guangdong over the period

b Pearson's chi-square test comparing number of cases by categories between 2009 and 11 and 2012-16

c Numbers of local and non-local cases do not sum up as the total number of cases because some cases had missing household registration data; chi-squared test nevertheless showed statistically significant result for cases with complete data on household registration

Since most infants in Guangdong who are eight months have already experienced a waning in their immunity [22], 94-96\% of them can successfully be seroconverted after vaccination [31]. However, advancing the MV1 delivery time to 6 months of age remains controversial [7], even though the World Health Organization suggests that infants aged $\geq 6$ months should have a supplementary MV before routine immunization if they are in high-risk settings like daycare facilities [29]. Aside from closing the immunity gap among 6-8-month-olds, protecting unvaccinated children via herd immunity and preventing transmission from older populations should be a primary focus [7].

The second reason for the surge of measles in $0-8$ month-olds was the increased number of infective individuals transmitting the virus to susceptible, unvaccinated infants. The increased infection rate among 9-23month-olds and 2-6-year-olds were due to the lower coverage in birth cohorts after the 2010 SIAs as well as the absence of extra doses offered by the SIAs [32]. At the same time, a multi-provincial study revealed that

Table 2 Age-specific incidences and median age of disease onset from 2009 to 2016

\begin{tabular}{|c|c|c|c|c|c|c|c|c|}
\hline Age group(s) & $\begin{array}{l}2009 \\
(n=2246)\end{array}$ & $\begin{array}{l}2010 \\
(n=640)\end{array}$ & $\begin{array}{l}2011 \\
(n=308)\end{array}$ & $\begin{array}{l}2012 \\
(n=1929)\end{array}$ & $\begin{array}{l}2013 \\
(n=7032)\end{array}$ & $\begin{array}{l}2014 \\
(n=6752)\end{array}$ & $\begin{array}{l}2015 \\
(n=2190)\end{array}$ & $\begin{array}{l}2016 \\
(n=1265)\end{array}$ \\
\hline \multicolumn{9}{|c|}{ Age-specific incidence $(s)^{a}$ (cases per 100,000) } \\
\hline $0-8$ months & 49.21 & 14.90 & 4.01 & 62.68 & 279.67 & 254.99 & 76.03 & 37.83 \\
\hline $\begin{array}{l}9-23 \\
\text { months }\end{array}$ & 31.06 & 14.23 & 3.90 & 31.30 & 95.60 & 79.73 & 24.51 & 14.29 \\
\hline $2-6$ years & 7.18 & 1.29 & 0.89 & 7.10 & 18.47 & 15.62 & 5.12 & 1.73 \\
\hline $7-15$ years & 1.39 & 0.34 & 0.17 & 0.63 & 2.25 & 2.44 & 1.21 & 0.35 \\
\hline 16-24 years & 1.97 & 0.69 & 0.42 & 0.60 & 2.49 & 2.54 & 0.84 & 0.48 \\
\hline$\geq 25$ years & 0.64 & 0.16 & 0.08 & 0.48 & 1.78 & 2.20 & 0.78 & 0.57 \\
\hline Total & 2.22 & 0.61 & 0.29 & 1.82 & 6.61 & 6.30 & 2.02 & 1.15 \\
\hline $\begin{array}{l}\text { Median (IQR) } \\
\text { age of } \\
\text { disease onset }\end{array}$ & $\begin{array}{l}4 \text { years ( } 10 \\
\text { months }-20 \text { years) }\end{array}$ & $\begin{array}{l}2 \text { years ( } 10 \\
\text { months } \\
-21 \text { years) }\end{array}$ & $\begin{array}{l}7 \text { years ( } 14 \\
\text { months } \\
-22 \text { years) }\end{array}$ & $\begin{array}{l}18 \text { months (8 } \\
\text { months } \\
-8 \text { years) }\end{array}$ & $\begin{array}{l}13 \text { months (8 } \\
\text { months } \\
-10 \text { years) }\end{array}$ & $\begin{array}{l}17 \text { months (8 } \\
\text { months } \\
-23 \text { years) }\end{array}$ & $\begin{array}{l}2 \text { years ( } 8 \\
\text { months } \\
-24 \text { years) }\end{array}$ & $\begin{array}{l}2 \text { years ( } 8 \\
\text { months } \\
-27 \text { years) }\end{array}$ \\
\hline
\end{tabular}

${ }^{a}$ Age-specific incidence is expressed as the number of cases reported divided by the population size of the age group

b Only ages $<2$ years old were reported by month-age, ages $\geq 2$ years old were reported by whole numbers

$I Q R$ Interquartile range 


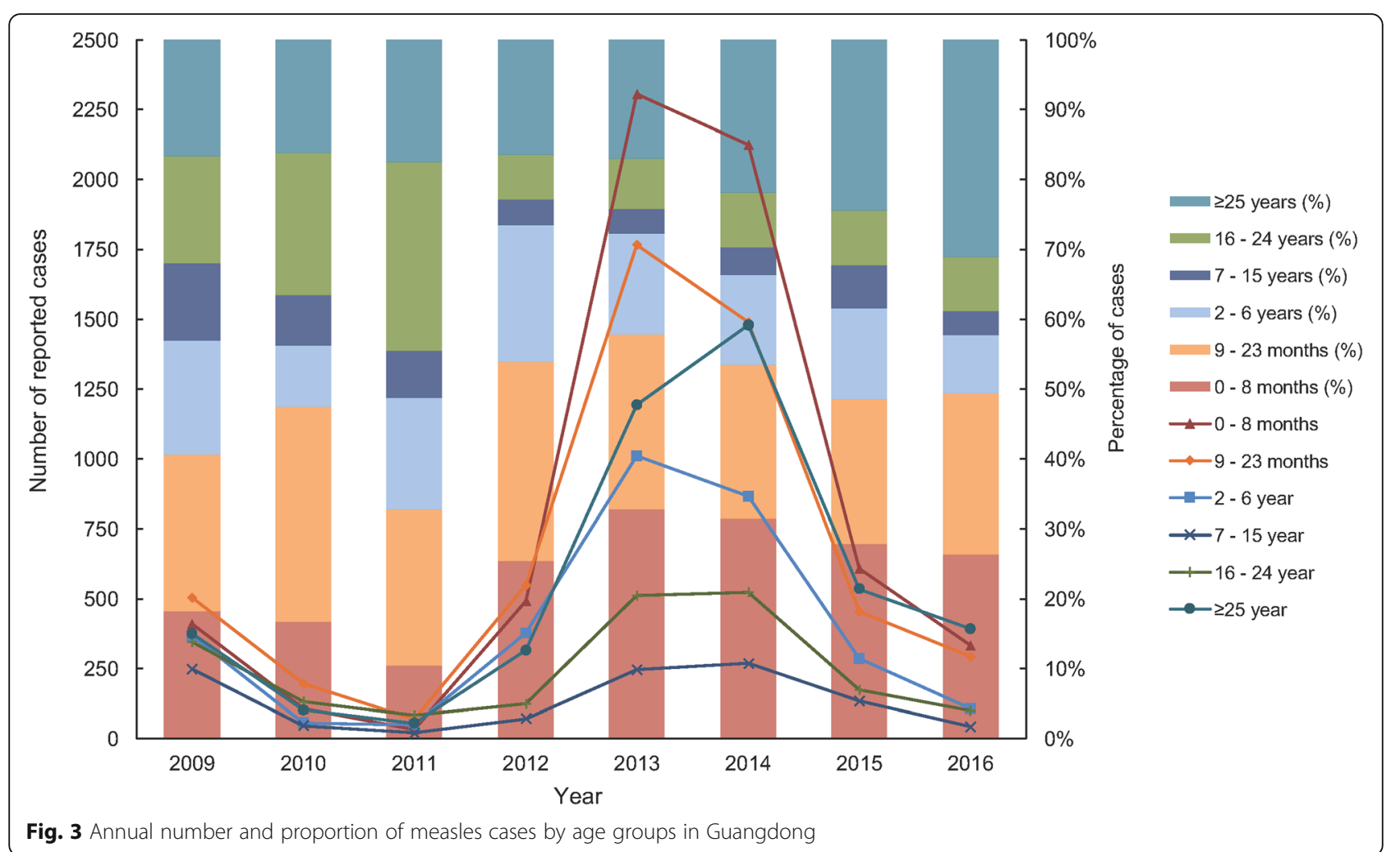

one of the most prevalent routes of exposure was hospital visits [33]. A case-control study in Guangdong province also showed that children who visited hospitals had an odds ratio of 5.50 of developing measles within one to three weeks compared to those who did not; this was the second most significant factor after nonvaccination [34]. Moreover, infants are prone to other illness and might visit healthcare facilities more frequently for medications and regular check-ups; thus, infection control in healthcare settings is crucial for reducing the incidence of measles. In our dataset, we found that 1136 infants diagnosed with measles during 2012-2013 who were $0-8$ months old (40.6\%) had visited hospitals 7-21 days before disease onset, while 1478
(52.8\%) had not and 183 (6.5\%) had an unknown hospital visit history. The proportion of patients having been exposed to hospital settings was slightly lower than that shown in the aforementioned multi-provincial study (45\%), with outpatient hospital visits being a significant predictor of infection (adjusted matched odds ratio 9.4) [33].

The rise in measles incidence rates among older age groups, especially the 9-23-month-old and 2-6-year-old groups, resulted from the aggregation of susceptible individuals after the province-wide SIAs were introduced, owing to lower vaccination coverage or primary vaccine failures. Low vaccination coverage among newly born cohorts after the 2010 SIAs was a key contributor to the national resurgence [32,35]. A recent survey conducted

Table 3 Proportion of different vaccination status of cases by age groups, 2009-2016

\begin{tabular}{|c|c|c|c|c|c|c|c|c|c|c|}
\hline \multirow[b]{2}{*}{ Age group(s) } & \multicolumn{5}{|l|}{$2009-2011$} & \multicolumn{5}{|l|}{$2012-2016$} \\
\hline & Number of cases (n) & 0 dose(\%) & $\begin{array}{l}1 \text { dose } \\
(\%)\end{array}$ & $\begin{array}{l}\geq 2 \text { doses } \\
(\%)\end{array}$ & $\begin{array}{l}\text { Unknown } \\
\text { (\%) }\end{array}$ & Number of cases (n) & $\begin{array}{l}0 \text { dose } \\
(\%)\end{array}$ & $\begin{array}{l}1 \text { dose } \\
(\%)\end{array}$ & $\begin{array}{l}\geq 2 \text { doses } \\
(\%)\end{array}$ & $\begin{array}{l}\text { Unknown } \\
\text { (\%) }\end{array}$ \\
\hline $0-8$ months & 548 & 66.1 & 7.3 & 0.0 & 26.4 & 5862 & 91.2 & 3.0 & 0.0 & 5.8 \\
\hline 9-23 months & 769 & 28.9 & 32.6 & 3.8 & 34.7 & 4551 & 70.7 & 15.1 & 0.4 & 13.7 \\
\hline 2-6years & 473 & 21.1 & 10.1 & 16.5 & 52.2 & 2646 & 53.7 & 9.6 & 7.6 & 29.1 \\
\hline $7-15$ years & 315 & 7.9 & 8.9 & 11.1 & 72.1 & 761 & 33.0 & 10.0 & 10.5 & 46.5 \\
\hline $16-24$ years & 558 & 20.6 & 5.0 & 1.4 & 73 & 1431 & 17.9 & 4.2 & 1.3 & 76.6 \\
\hline$\geq 25$ years & 531 & 16.6 & 2.4 & 0.6 & 80.4 & 3917 & 16.4 & 2.0 & 0.4 & 81.3 \\
\hline Total & 3194 & 28.6 & 12.8 & 4.8 & 53.9 & 19,168 & 58.1 & 7.0 & 1.8 & 33.2 \\
\hline
\end{tabular}


in Guangdong revealed that MV1 coverage was $71.8 \%$ among migrant children aged 12-59 months, and that only $37.2 \%$ had MV1 administered in the appropriate time [36]. On the other hand, increased vaccination coverage among children $\geq 8$ months had very positive effects on providing herd immunity to those $\leq 8$ months. Owing to the SIAs in 2009 and 2010, incidence in every age group dropped by $60-85 \%$ in 2010 ; interestingly, only the $0-8$ and 9-23-month-old groups had similar and substantial drops in the number of cases in 2011 as they did in 2010 (i.e., decreases of 70 and $60 \%$ respectively).

Comparing across age groups, we showed that the proportions of patients with measles aged 7-15 years and 1624 years had dropped significantly between 2009 and 2011 and 2012-2016, as they were covered by the SIAs. Proportion of 7-15 and 16-24 years old cases were higher during 2009-2011 (9.9 and 17.5\% respectively) but lower during 2012-2014 (4.0 and 7.5\% respectively), indicating the effectiveness of SIAs in protecting the cohorts against outbreaks. However, similar to other Chinese provinces at the time, Guangdong experienced increasing proportions of adults with the disease from 2014 to 2016; adults accounted for the highest number of diagnoses in 2016. Relatively high proportions of adult patients were also observed after the SIAs were introduced in other studies [20, 21]. The decreasing incidence in the overall population, declining birth rate, and increasing vaccination coverage among infants and children compared to the low coverage rate in the 1980s and earlier [37, 38] all contributed to the increasing mean age of infection and build-up of susceptible individuals among adults [39]. In China, infections among adults were mainly due to susceptibility caused by missed vaccinations and decreased opportunities for acquiring immunity through natural infection $[38,40]$. As revealed in our study and others, the majority of infected adults were either unvaccinated or had an unknown vaccination history $[41,42]$.

Various vaccination strategies have been suggested for reducing the number of susceptible individuals among infants, eligible children, and adults. First, for infants with waned maternal immunity, MV1 was not recommended at any time earlier than eight months of age on a routine immunization basis, as infants with maternal immunity that did not wane below a certain threshold would experience vaccine failure $[43,44]$. An additional MV is suggested for infants six months of age in cases of outbreaks; these should be followed by MV1 and MV2 per the regular schedule [29, 45]. Second, for 8-month- and 18-24month-old children eligible for MV1 and MV2, respectively, responsible authorities should maintain a high coverage and timely delivery of routine immunization through frequent monitoring and coverage assessment [32]. Lastly, investigations on adult susceptibility, especially in terms of secondary vaccine failure, were needed, and procedures to reduce susceptibility among adults might be warranted [42]. Although the World Health Organization and some studies have highlighted the successes of adult-targeted SIAs [46, 47], mass immunization campaigns targeting adult susceptibility were not recommended because selective and targeted SIAs; i.e., revaccination of school students, women of child-bearing ages, and populations susceptible to outbreaks, were rightfully deemed more appropriate and useful than nonselective SIAs [40, 42].

On case distribution by cities during 2013 outbreak, Guangzhou and Shenzhen had high number of cases because the two cities hosted $21.6 \%$ of total population in Guangdong and had very high proportions of migrants population [48], among whom incidence was higher and age-appropriate MCV uptake rate was low [36, 49]. As for Huizhou, a city with lower population density and fewer migrants [48], incidence among MCV-eligible children was very high; 9-11 months old cases alone accounted for $24.8 \%$ of total cases in 2013 [50]. In Zhanjiang city with low population density and a net outflow of population, incidence among the 12-23 months old was as high as 122.9 per 100,000 in 2013 [51]. The two cities also had higher percentages of cases with no or unknown immunization history $(89.8 \%$ in Zhanjiang overall and $88.2 \%$ in Huizhou among 8 months - 14 years old cases) compared to Guangdong. Missing or delayed routine immunization is yet to be addressed so as to control measles in the two cities.

There were several limitations in this study. First is the possible underestimation of measles cases because some patients might not present to local doctors. Second is the limited analysis of the effectiveness of the two SIAs owing to the lack of measles data for several years before the SIAs were introduced in 2009. In our study, we focused on newly born cohorts after the SIAs (0-23-month-olds in and after 2012). Unlike those who were born in 20092010 and were protected by the herd immunity provided by older age groups (the 8 month- to 14-year-olds in 2009 and the 8 month- to 4 year-olds in 2010 , respectively), newborns in 2012 or later had older ( $\geq 8$-month-old) counterparts who did not receive additional vaccine doses administered through the SIAs. Therefore, the effectiveness of SIAs in terms of influencing the incidence of measles among newborns born within or outside their implementation periods could be assessed by examining the changes in epidemiological characteristics (e.g. age distribution) during the post-SIA resurgence in 2013. Third, the reported vaccination coverage periods for the two SIAs were only administrative estimates, and were likely slightly overestimated. Our main focus was on how newborns were protected by the herd immunity of different cohorts whether subject to the SIAs or not, and we posit that the overestimation of the administrative coverages would not 
appreciably affect the conclusions of our analysis since the total vaccinated population still accounted for an overwhelming majority of the population (e.g., $\geq 19.9$ million vaccinated individuals in 2009 accounted for 93.9\% of population in the eligible age range). Fourth, the routine immunization coverages during the study period were not provided to correlate with the age-specific incidence, due to possible over-estimation. Susceptibility among different age groups were discussed in correspondence with the different vaccination strategies targeting every individual in specific age groups (e.g. routine immunization for the 8 and the 18-24 months old, SIAs for the 8 months old to 14 years old in 2009), and therefore the trend of incidence in different age groups reflected effectiveness of those interventions in different age groups. Fifth, the vaccination history of the majority of individuals $\geq 16$ years of age were unknown, although the percentage of unknown vaccination history was small among young children between 2012 and 2016; this limited our analysis on vaccination history. Lastly, the study was of limited statistical power owing to its secondary data analysis design that lacked a hypothesis-driven sample size planning.

\section{Conclusions}

Although Guangdong province has implemented province-wide routine immunizations and SIAs with remarkably successful results, measles transmission has persisted. The 2013 resurgence of this disease revealed insufficient immunization coverage among children. Enhancing routine immunization and protecting infants from exposure are important plans of action, as infants who are ineligible for MV or eligible only for a single dose are the most susceptible to outbreaks, and contributed most to the resurgence in 2013. Future studies on the practicality of immunization strategies targeting susceptible infants and adults are required to collectively reduce infections.

\section{Supplementary information}

Supplementary information accompanies this paper at https://doi.org/10. 1186/s12879-020-4919-x.

Additional file 1. Distribution of measles cases by month-age among $\leq 8$ month old cases in each year. A single pdf file with 1 page, the figure embedded.

\section{Abbreviations}

SIAs: Supplementary immunization activities; MVs: Measles vaccine; MV1: Measles vaccine (first dose); MV2: Measles vaccine (second dose); NIDMIS: National Infectious Disease Monitoring Information System; CDC: Center for Disease Control and Prevention

\section{Acknowledgements}

We thank Guangdong CDC for providing the data for analysis, and the National Earth System Science Data Sharing Infrastructure, National Science \& Technology Infrastructure of China (http://www.geodata.cn) for providing part of the population data.

\section{Authors' contributions}

$\mathrm{KCC}$ and RS conceived the study. KMJ and RS performed the analysis. WL, $\mathrm{PH}$, and $\mathrm{HZ}$ contributed to the acquired data of the study. $\mathrm{WL}, \mathrm{PH}, \mathrm{HZ}, \mathrm{MHW}$, $B C Y Z$, and RS contributed to the results interpretation. RS, KCC, and KMJ drafted the paper. All authors have read and approved the final paper.

\section{Funding}

This work was supported by the Basic research project from Shenzhen Municipal Science and Technology Program [JCYJ20150630165236958] the National Natural Science Foundation of China [81473035, 71974165]. The funding bodies do not have any role in the design of the study and collection, analysis, and interpretation of data and in writing the manuscript.

\section{Availability of data and materials}

The original datasets used in the study area are available from the Guangdong Provincial Center for Disease Control and Prevention. Datasets were used under license for the current study, and so are not publicly available. Data are, however, available from the authors upon reasonable request and with permission of the Guangdong Provincial Center for Disease Control and Prevention.

\section{Ethics approval and consent to participate}

This study was reviewed and approved by the Medical Ethics Committee of the Guangdong CDC. Informed consent was waived by the Committee, as the data were collected for the purpose of routine public health surveillance activities. The data were anonymized before analysis.

\section{Consent for publication}

Not applicable.

\section{Competing interests}

All authors declare that they have no competing interests.

\section{Author details}

${ }^{1}$ Center for Disease Control and Prevention of Guangdong Province, Guangzhou, China. ${ }^{2}$ Jockey Club School of Public Health and Primary Care, The Chinese University of Hong Kong, Hong Kong, China. ${ }^{3}$ Clinical Trials and Biostatistics Laboratory, Shenzhen Research Institute, The Chinese University of Hong Kong, Shenzhen, China.

Received: 23 February 2019 Accepted: 26 February 2020

Published online: 06 March 2020

\section{References}

1. World Health Organization. Fact sheet: Measles. WHO Media Centre. 2018. http://www.who.int/mediacentre/factsheets/fs286/en/\#. Accessed 10 Apr 2018.

2. World Health Organization Representative Office China. Measles: key facts. 2018. http://www.wpro.who.int/china/mediacentre/factsheets/measles/en/. Accessed 13 Jul 2018.

3. Ma C, Hao L, Zhang Y, Su Q, Rodewald L, An Z, et al. Monitoring progress towards the elimination of measles in China: an analysis of measles surveillance data. Bull World Health Organ. 2014;92(5):340-7.

4. $\mathrm{Ma}$ C, An Z, Hao L, Wen N, Ao C, Cao L, et al. Progress toward measles elimination in the People's republic of China, 2000-2009. J Infect Dis. 2011; 204(Suppl. 1):447-54.

5. Bureau of Disease Prevention. General Description of National Statutory Infectious Diseases in 2016. Infectious Disease Prevention and Control. 2017. http://www.nhfpc.gov.cn/jkj/s3578/201702/38ca5990f8a54ddf9ca6308fec4 06157.shtml. Accessed 19 Aug 2017. [Article in Chinese].

6. Ma C, Su Q, Hao L, Wen N, Ao C, Cao L, et al. Measles Epidemiology Characteristics and Progress Toward Measles Elimination in China, 20122013. Chinese J Vaccines Immun. 2014;20(3):193-200 Article in Chinese.

7. Ma C, Hao L, Su Q, et al. Measles epidemiology in China, 2014. Dis Surveill. 2015:30(10):818-82 Article in Chinese.

8. Ma R, Lu L, Zhang Z, Suo L, Li J, Chen M, et al. Changes of epidemiological characteristics of measles in Beijing before and after supplementary immunization campaigns of measles vaccine in 2010. Chinese J Prev Med. 2015:49(12):1036-41 Article in Chinese.

9. Li L, Yu W, Shui T, Ma C, Wen N, Liang X. Analysis on Epidemiological Characteristics of Age Distribution of Measles in China During 2003-2006. Chinese J Vaccines Immun. 2007;13(2):101-5 Article in Chinese. 
10. Tan Q, Wu C, Peng C, Shu J. Measles Epidemiological Characteristics in Guangdong, 2004-2008. South China J Prev Med. 2010;36(2):42-5 Article in Chinese.

11. Han K. Study on measles epidemiology characteristics, and elimination strategies in Guangdong provinces at measles vaccine widely using area. 2016. [Article in Chinese].

12. Li B, Du Y. Spatiotemporal change of Guangdong population distribution during the last 30 years. J Inner Mongolia Normal University (Natural Science Edition). 2017;46(6):861-5 Article in Chinese.

13. Zhu X. The Yearbook of Guangdong. 2016. [Article in Chinese].

14. Liang Z, Li Z, Ma Z. Changing patterns of the floating population in China during 2000-2010. Popul Dev Rev. 2014;40(4):695-716.

15. Goodkind D, West LA. China's floating population: definitions, Data and Recent Findings. Urban Stud. 2002;39(12):2237-50.

16. Centers for Disease Control and Prevention Guangdong. Notice on the freeof-charge routine immunizatoin program in Guangdong. 2016. http://www. cdcp.org.cn/gdsjbyfkzzx/gdsymjzmz/201011/d5314181ae7242a1b03eef9ab4 b574cb.shtml?time=0.9443900562169961. Accessed 19 Feb 2019. [Article in Chinese].

17. Atkinson WL, Pickering LK, Schwartz B, Weniger BG, Iskander JK, Watson JC. General Recommendations on Immunization. MMWR Morb Mortal Wkly Rep. 2002;51(RR02):1-36.

18. R software [Internet]. Available from: www.r-project.org.

19. Guo Z, Zhou J, Liu Y, Yang Y. Epidemiology analysis and strategic planning in 3162 hospitalized measles cases. Chin J Infect Dis. 2011;29(5):314-5 Article in Chinese.

20. Chen J, Pan W, Cai C, Zhou Y, Lin Z. Analysis on Epidemiological Characteristics of Measles in Fujian, 2006-2013. Prev Med Trib. 2015;21(2): 155-9 Article in Chinese.

21. Wang X, Boulton ML, Montgomery JLP, Carlson B, Zhang Y, Gillespie B, et al. The epidemiology of measles in Tianjin, China, 2005-2014. Vaccine. 2015; 33(46):6186-91.

22. Tang C, Chen S, Zhang Q, Mo X, Lin R, Wang Y. Surveillance on the antibody level of measles in natural population in Dongguan City, 2013. Pract Prev Med. 2016;23(12):1444-7 Article in Chinese.

23. Lu L, Cao YM, Yang QY, He Q, Dong ZQ, Di B, Fu CX, Wang M. Dynamic maternal measles antibody level in infants: a longitudinal study. Chinese J Epidemiol. 2016:37(5):663-7 Article in Chinese.

24. Zhang X, Shirayama Y, Zhang Y, Ba W, Ikeda N, Mori R, Shibuya K. Duration of maternally derived antibody against measles: a seroepidemiological study of infants aged under 8 months in Qinghai. China. Vaccine. 2012;30(4):752-7.

25. Brugha R, Ramsay M, Forsey T, Brown D. A study of maternally derived measles antibody in infants born to naturally infected and vaccinated women. Epidemiol Infect. 1996;117(3):519-24.

26. van den Hof S, Berbers GA, de Melker HE, Conyn-van Spaendonck MA. Seroepidemiology of measles antibodies in the Netherlands, a cross-sectional study in a national sample and in communities with low vaccine coverage. Vaccine. 1999;18:931-40

27. Leuridan E, Hens N, Hutse V, leven M, Aerts M, Van Damme P. Early waning of maternal measles antibodies in era of measles elimination: Iongitudinal study. BMJ. 2010;340:c1626

28. Guerra FM, Crowcroft NS, Friedman L, Deeks SL, Halperin SA, Severini A, Hatchette TF, Bolotin S. Waning of measles maternal antibody in infants in measles elimination settings-a systematic literature review. Vaccine. 2018;36(10):1248-55.

29. World Health Organization. WHO recommendations for routine immunization - summary tables. 2019. https://www.who.int/immunization/ policy/immunization_tables/en/. Accessed 14 Aug 2019.

30. Rota PA, Moss WJ, Takeda M, de Swart RL, Thompson KM, Goodson JL. Measles. Nat Rev Dis Prim. 2016:2:16049.

31. Himan A. Recommendation on measles control strategies in China. Chinese J Vaccines Immunization. 2002;8(2):111-5.

32. Ma C, Li F, Zheng X, Zhang H, Duan M, Yang Y, et al. Measles vaccine coverage estimates in an outbreak three years after the nation-wide campaign in China: implications for measles elimination, 2013. BMC Infect Dis. 2015;15(1):23.

33. Ma C, Gregory CJ, Hao L, Wannemuehler KA, Su Q, An Z, et al. Risk factors for measles infection in 0-7 month old children in China after the 2010 nationwide measles campaign: a multi-site case-control study, 2012-2013. Vaccine. 2016:34(51):6553-60.

34. He Z, Peng Z, Lin Y, Liang J, Yang W, Chen C, Xu L, Huang G, He J. Factors of measles cases occurrence in Guangdong. South China J Prev Med. 2009; 35(1):47-8 Article in Chinese.
35. Chong KC, Zhang C, Zee BCY, Luo T, Wang L, Tam GCH, et al. Interpreting the transmissibility of measles in two different post periods of supplementary immunization activities in Hubei. China Vaccine. 2017;35(7):1024-9.

36. Han $\mathrm{K}$, Zheng $\mathrm{H}$, Huang Z, Qiu Q, Zeng H, Chen B, et al. Vaccination coverage and its determinants among migrant children in Guangdong, China. BMC Public Health. 2014;14(1):203.

37. Li S, Ma C, Hao L, Su Q, An Z, Ma F, et al. Demographic transition and the dynamics of measles in six provinces in China: a modeling study. PLoS Med. 2017;14(4):e1002255.

38. Zhang M, Ai J, Li Y. Measles Outbreak among Adults, Northeastern China, 2014. Emerg Infect Dis. 2016;22(1):144-6.

39. Chong KC, Hu P, Lau SYF, Jia KM, Liang W, Wang MH, et al. Monitoring the age-specificity of measles transmissions during 2009-2016 in southern China. PLoS One. 2018;13(10):e0205339.

40. He H, Chen EF, Li Q, Wang Z, Yan R, Fu J, et al. Waning immunity to measles in young adults and booster effects of revaccination in secondary school students. Vaccine. 2013:31(3):533-7.

41. Zheng X, Zhang N, Zhang X, Hao L, Su Q, Wang H, et al. Investigation of a measles outbreak in China to identify gaps in vaccination coverage, routes of transmission, and interventions. PLoS One. 2015;10(7):e0133983.

42. Ma C, Yan S, Su Q, Hao L, Tang S, An Z, et al. Measles transmission among adults with spread to children during an outbreak : implications for measles elimination in China, 2014. Vaccine. 2016;34(51):6539-44.

43. Biellik R, Clements CJ. Strategies for minimizing nosocomial measles transmission. Bull World Health Organ. 1997;75(4):367-75.

44. McKee A, Shea K, Ferrari MJ. Optimal vaccine schedules to maintain measles elimination with a two-dose routine policy. Epidemiol Infect. 2017;145(2): 227-35

45. World Health Organization. Measles vaccines: WHO position paper - April 2017. Wkly Epidemiol Rec. 2017;92(17):205-27.

46. World Health Organization. Regional strategy and plan of action for measles and rubella elimination in the Western Pacific. 2018.

47. Chong KC, Zhang C, Jia KM, Zee B, Luo T, Wang L, et al. Targeting adults for supplementary immunization activities of measles control in Central China: a mathematical Modelling study. Sci Rep. 2018:8:16124.

48. Statistics Bureau of Guangdong Province. Guangdong Statistical Yearbook 2014. 2019. http://stats.gd.gov.cn/gdtjnj/content/post_1424893.html. Accessed 22 Dec 2019

49. Wang W. Measles surveillance results analysis of Shenzhen city in 2013. J Med Pest Control. 2015;31(5):579-81 Article in Chinese.

50. Zeng J, Liu Y, Yang J, Ju X, Wang Y. Analysis on epidemiological characteristics and the detection results of measles in Huizhou 2012-2014. J of Pub Health and Prev Med. 2015;26(6):36-9 Article in Chinese.

51. Qi P, He G, Zheng Y, Chen J. Analysis on epidemiological characteristics of measles in Zhanjiang from 2004 to 2013 and the measures to eliminate measles. J Guangdong Med College. 2015;33(2):17-21.

\section{Publisher's Note}

Springer Nature remains neutral with regard to jurisdictional claims in published maps and institutional affiliations.

Ready to submit your research? Choose BMC and benefit from:

- fast, convenient online submission

- thorough peer review by experienced researchers in your field

- rapid publication on acceptance

- support for research data, including large and complex data types

- gold Open Access which fosters wider collaboration and increased citations

- maximum visibility for your research: over $100 \mathrm{M}$ website views per year

At BMC, research is always in progress.

Learn more biomedcentral.com/submissions 